\title{
二三 食用䒩菌のエルゴステリン量
}

熟 兒 瑞 襍

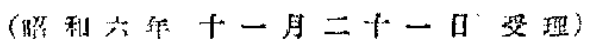

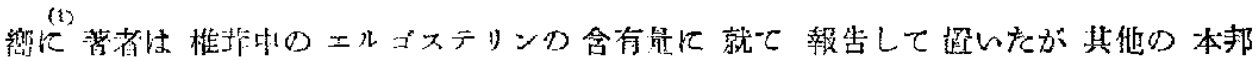

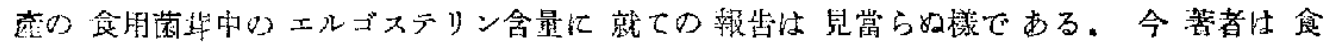

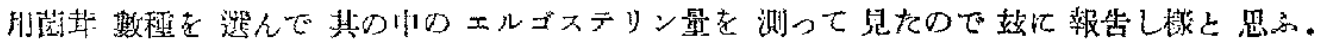

\section{其一 䧴茸の 部分に 依る エルゴスデリン量}

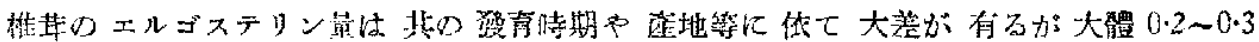

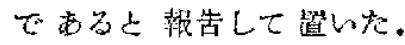

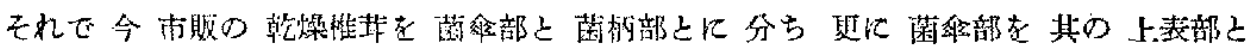

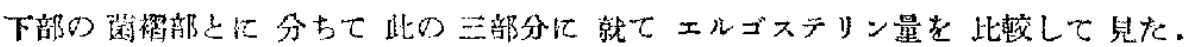

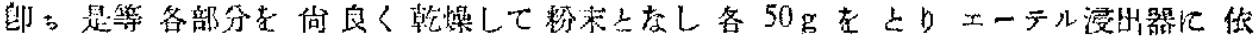

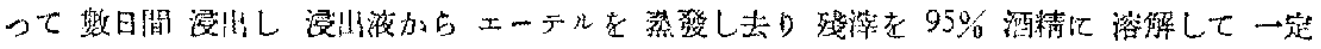

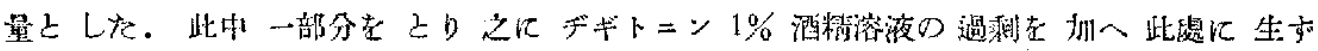

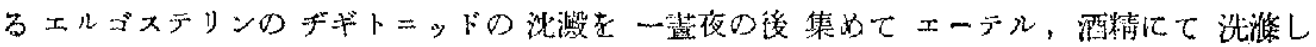

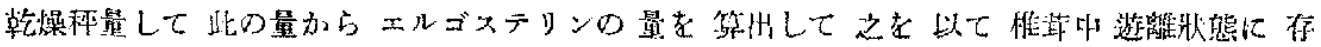
在するエルゴステリンの量上した。

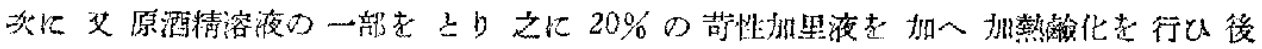

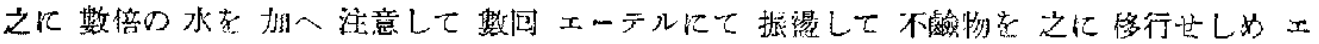

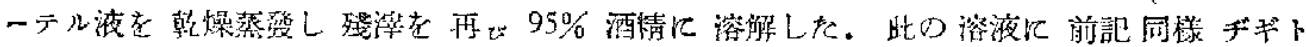

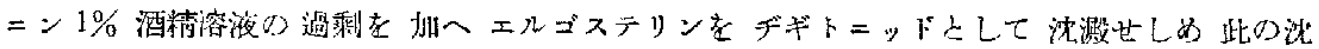

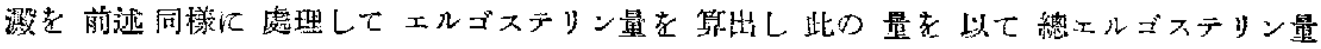

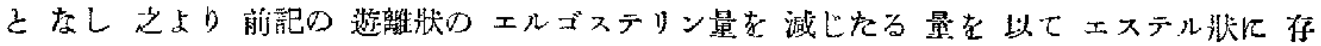
在するェルゴステリン量とした。

第一裁一椎苦の部分に永るエルゴスデリン量

\begin{tabular}{|c|c|c|c|c|}
\hline 椎革 部分 & $\begin{array}{l}\text { 甾部の } \\
\text { 重星比 }\end{array}$ & 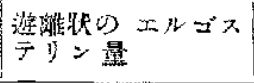 & 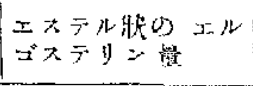 & $\begin{array}{l}\text { 總エルゴス } \\
\text { テリン量 }\end{array}$ \\
\hline 菌酿上表皮 & 37 & 0.2261 & 0.0233 & 0.2494 \\
\hline 菌 傘 部 & 43 & 0.3013 & 0.0312 & 0.3325 \\
\hline 橉 唡 部 & 20 & 0.1324 & 0.0136 & $0 \cdot 1460$ \\
\hline
\end{tabular}

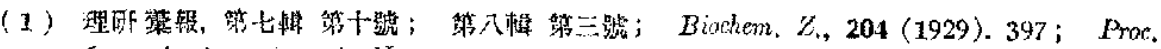
Imp. Acad., 4 (1928), No. 3. 


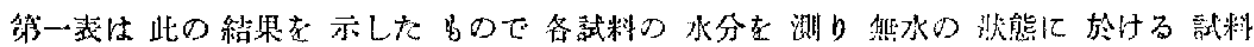

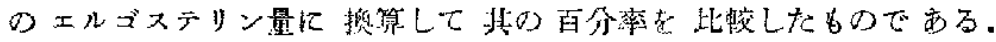

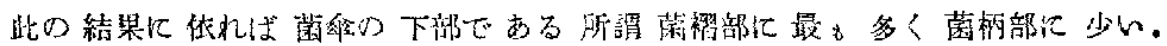

其二 椎荣の發育とエルゴステリン含量の 變化

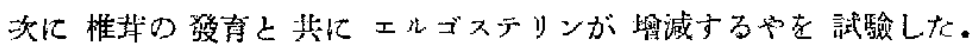

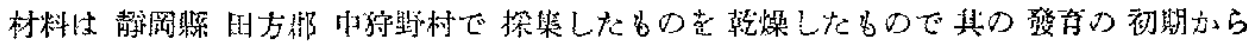

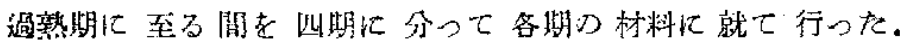

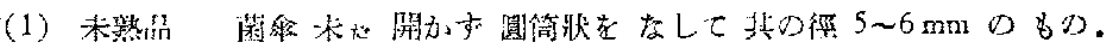

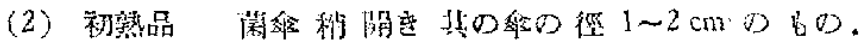

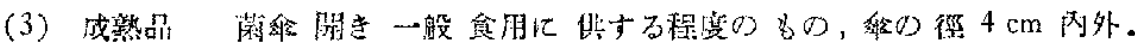

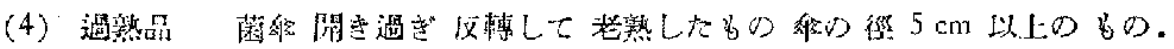

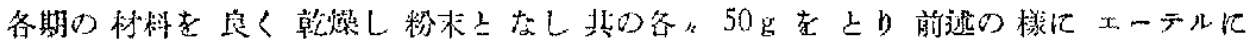

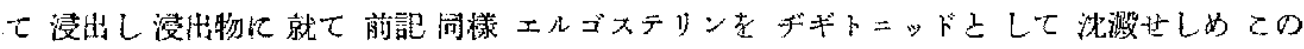

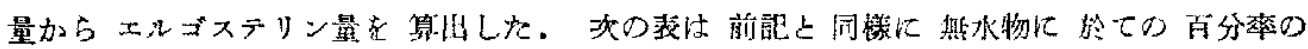
比である。

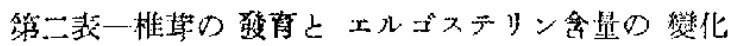

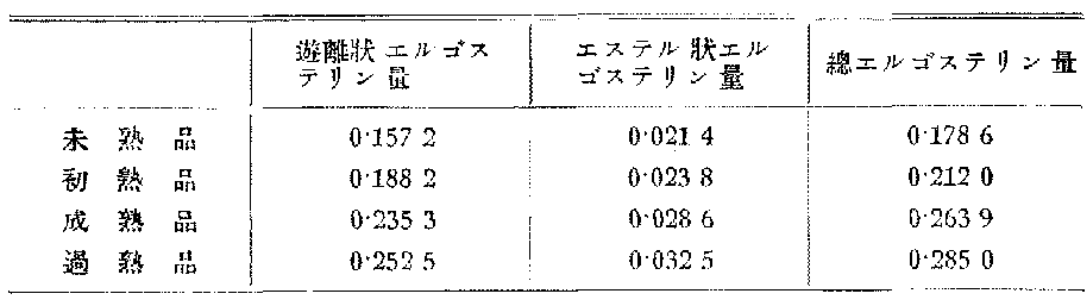

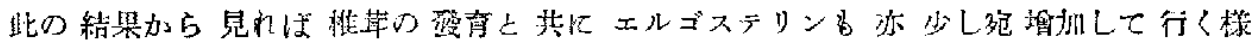
でする。

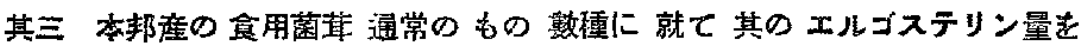 比較して見た}

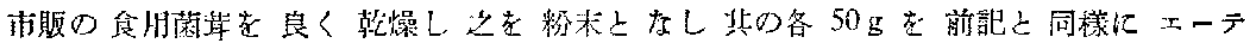

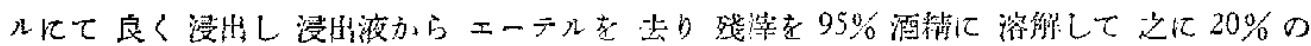

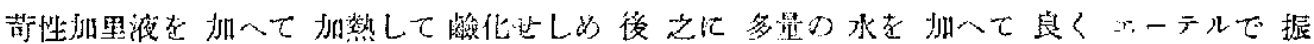

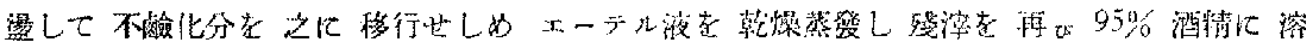

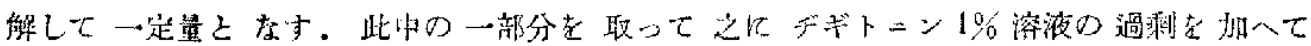

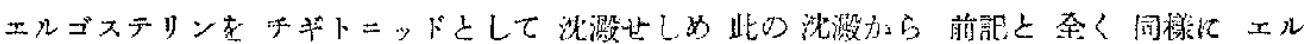

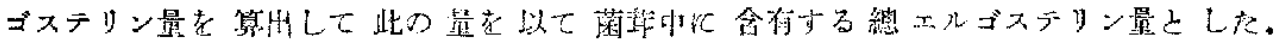

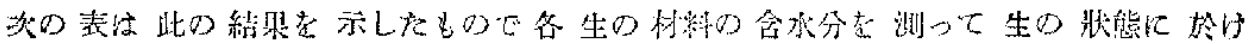

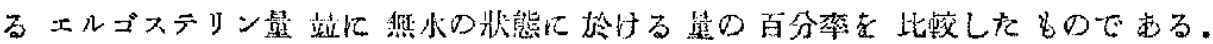




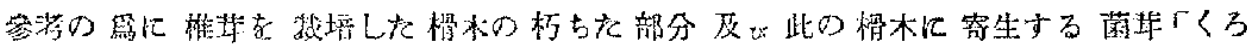

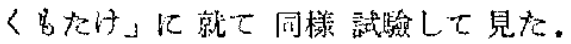

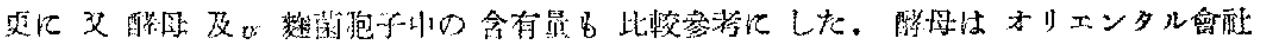

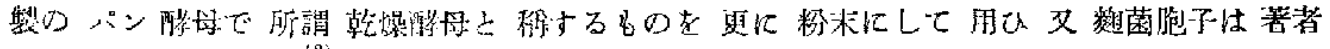

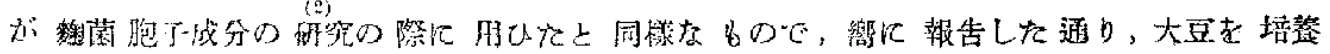

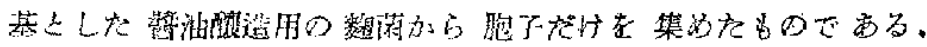

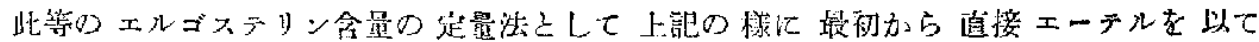

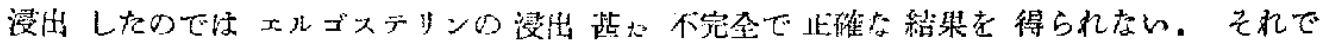

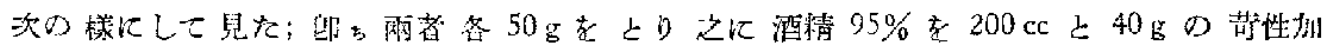

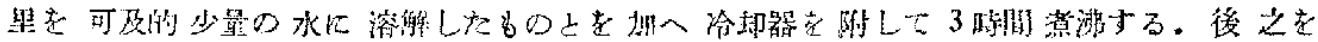

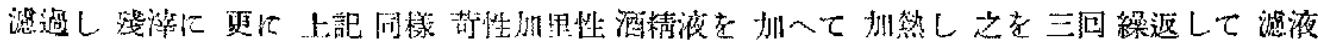

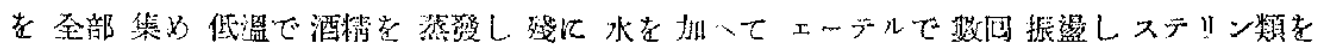

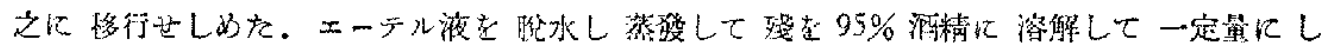

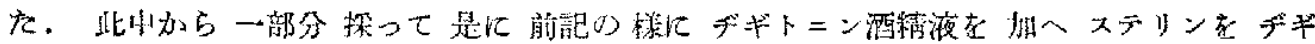

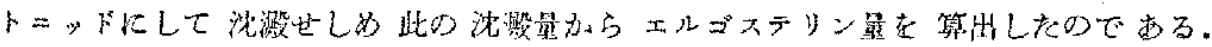

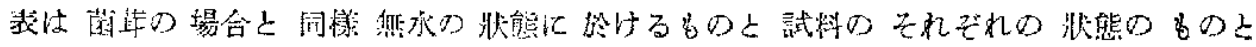

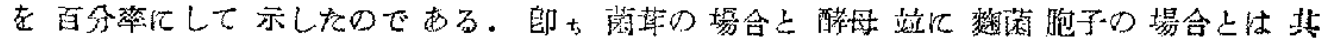

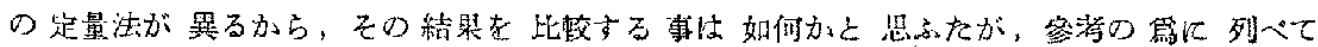
裴示して。

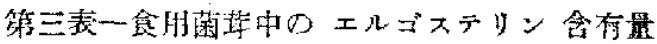

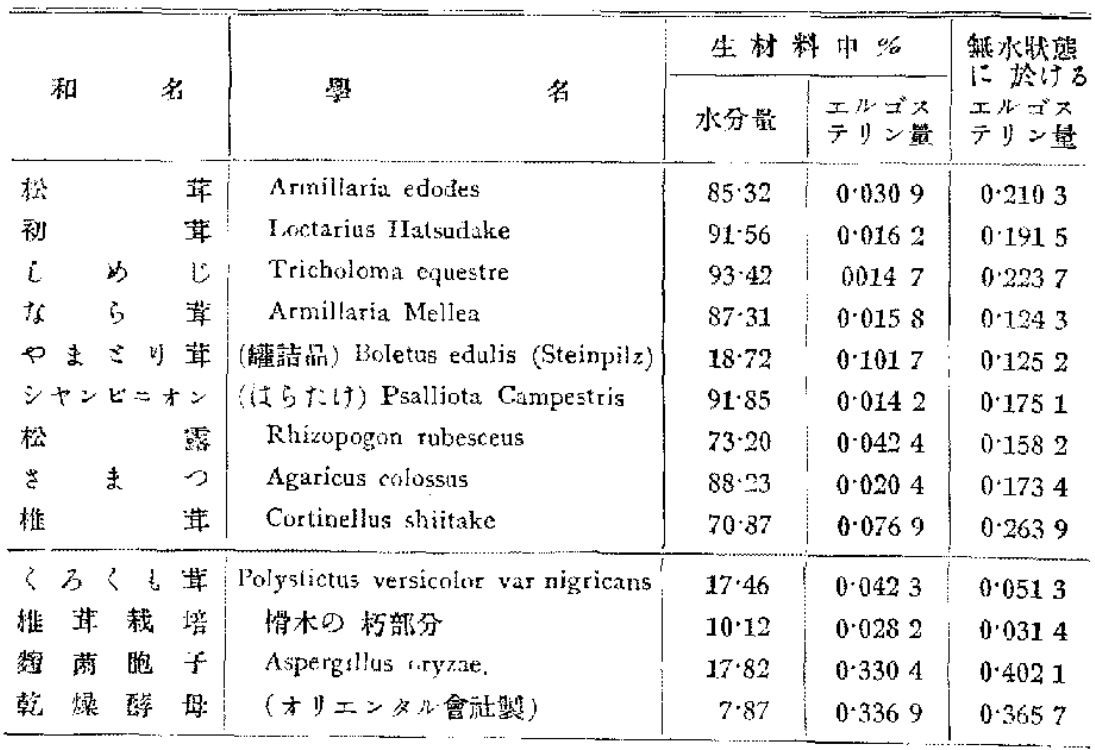

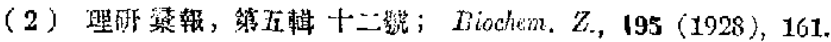


總括

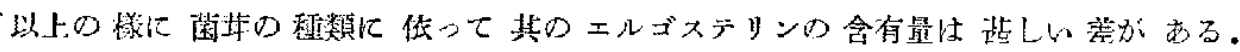

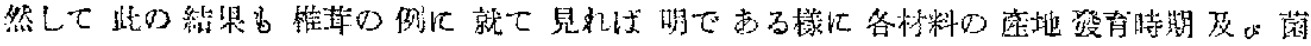

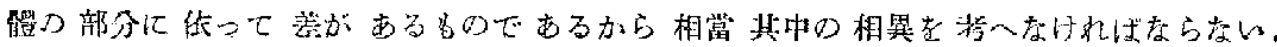

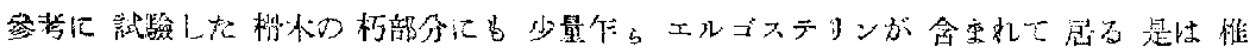

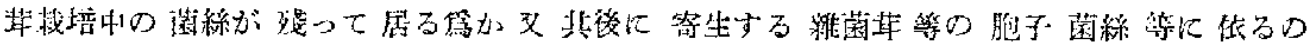
ではなるかと䍐梳れる。

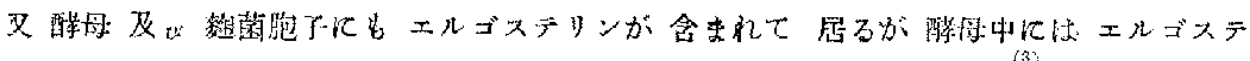

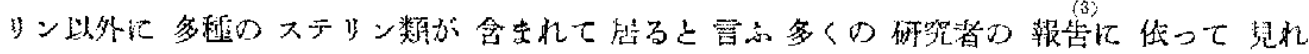

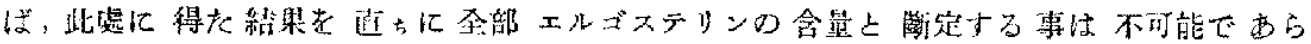
5 .

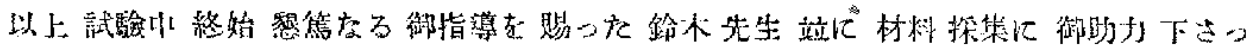

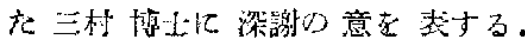

(3) II. WIEJAND and M. AsAno: Ann., 473 (1929), 300. GodrII: Ann., $482(1930), 36$.

$"$ W. STANLEY: Ann, $489(1931), 31$ 